This item was submitted to Loughborough's Research Repository by the author.

Items in Figshare are protected by copyright, with all rights reserved, unless otherwise indicated.

\title{
Tailoring thermal profiles for the reflow of SMD assemblies
}

PLEASE CITE THE PUBLISHED VERSION

PUBLISHER

(C) IEEE

LICENCE

CC BY-NC-ND 4.0

REPOSITORY RECORD

Tang, A.C.T., David C. Whalley, and David J. Williams. 2019. "Tailoring Thermal Profiles for the Reflow of SMD Assemblies". figshare. https://hdl.handle.net/2134/3974. 
This item was submitted to Loughborough's Institutional Repository (https://dspace.lboro.ac.uk/) by the author and is made available under the following Creative Commons Licence conditions.

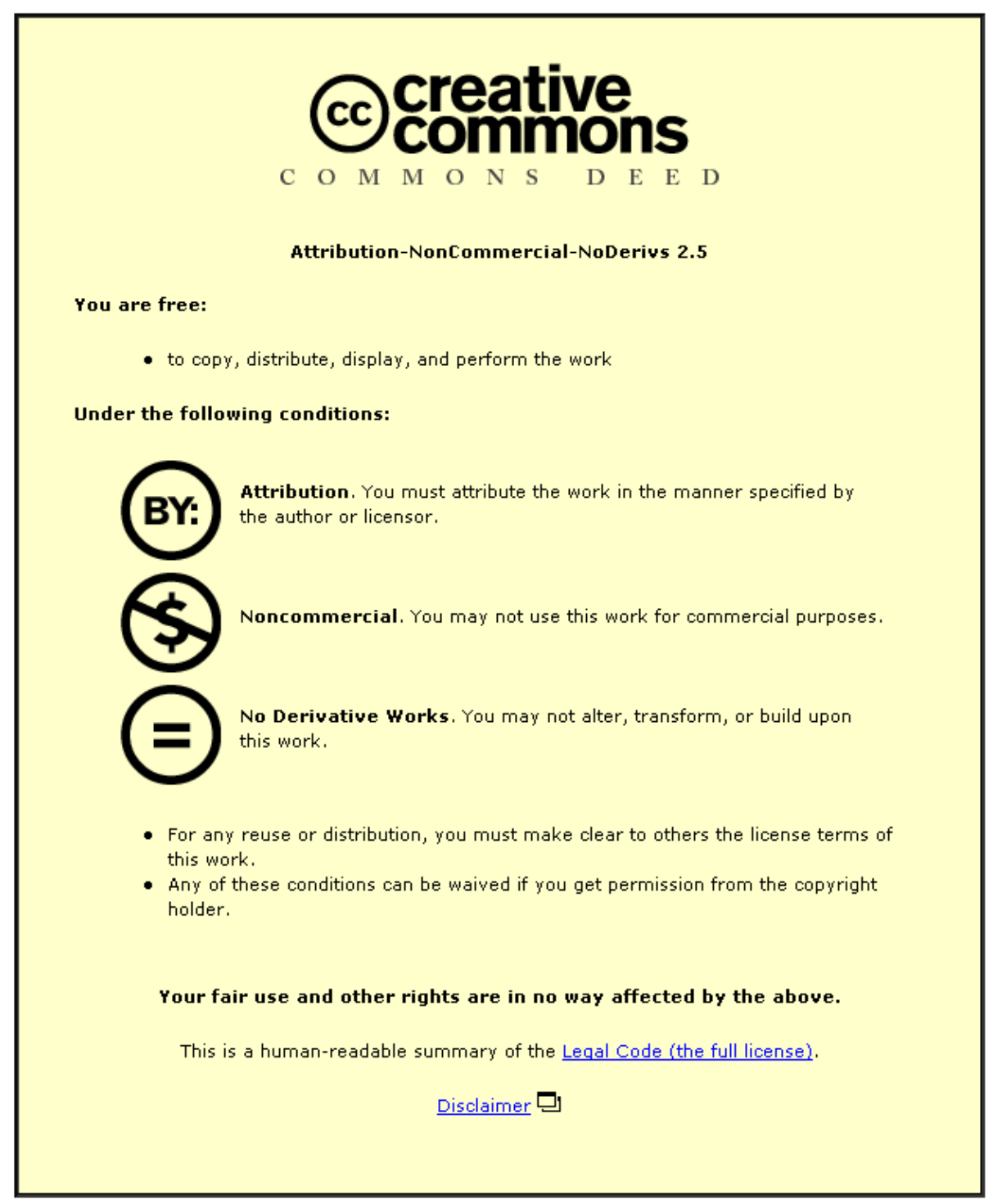

For the full text of this licence, please go to: http://creativecommons.org/licenses/by-nc-nd/2.5/ 


\title{
TAILORING THERMAL PROFILES FOR THE REFLOW OF SMD ASSEMBLIES
}

\author{
A.C.T.Tang \\ Cambridge University Engineering Department, \\ Trumpington Street, \\ Cambridge CB2 1PZ \\ England. \\ D.C.Whalley \& D.J.Williams \\ Department of Manufacturing Engineering, \\ Loughborogh University of Technology, \\ Loughborogh LE11 3TU \\ England.
}

\begin{abstract}
The aim of the work presented here is to investigate the effects of various types of thermal components (also known as heat thieves / barriers) on the thermal profiles of a printed circuit board. It is of great industrial importance to generate uniform thermal profiles for the IR reflow soldering of SMD assemblies. Temperature variations across a PCB have been identified as one of the principal manufacturing parameters likely to affect process yield.

Results from this work show that the thermal profiles of the PCB can be tailored. This is achieved by surrounding the PCB with different materials such as copper, alumina and graphite in a strip or ring formation. This has the effect of altering the distribution of the thermal properties of the system. Results of using the model show that by attaching an alumina strip to the outer edge of the PCB, the temperature differential of the PCB can be reduced to less than five degrees.
\end{abstract}

\section{INTRODUCTION}

The considerable variety of Surface Mount Device (SMD) terminations, solder pad shapes, soldering processes and properties of solder pastes have given rise to ill-understood and ad hoc methods and process specifications for electronics manufacturing. It is widely recognised that work is needed to establish preferred termination and pad designs, joint geometry, soldering parameters and joining process parameters for high volume manufacture and high reliability joint production.

Increased yield in the manufacturing process without sacrificing long term product reliability can be achieved by both better understanding of and compensating for the above process variables.

The current trends towards fine pitch and high joint counts per board have resulted in a larger proportion of SMDs' requiring rework. The defect rate per joint must therefore be reduced in order to maintain and improve first-off production yields. In order to meet this requirement, a fuller understanding of the soldering process and its key variables is required. This problem is best approached by developing a process model since, the understanding of the effects of these key variables has proved difficult to achieve through experimental analysis. This has been for the following reasons:-

a) The large number of variables that have been identified as affecting the soldering process and the complex interactions between these variables, see for example the discussion presented in [1].

b) The very small defect rate that it is necessary to now attempt to achieve ( $<1$ defect per million joints) requires very large numbers of experiments to be carried out in order to have any statistical confidence in the results.
Infra Red (IR) is currently the most common reflow technique used in the surface mount industry. The inherent advantages of radiant heating for the reflow soldering of SMDs' are that firstly, there is no contact with the workpiece thus reducing the possibility of contamination and the need for extra cleaning. Secondly, the heat source can be remote, enabling heat transfer into chambers under vacuum or other inert environment. Furthermore, the equipment can be manufactured and installed at significantly lower cost than that required for other reflow techniques.

The soldering process may be divided into two major stages; pre-reflow preparation and reflow. The former includes the bringing together of a well-characterised solder paste with a PCB and components which are both solderable and of appropriate geometry. It is of extreme importance that the correct volume of solder paste is placed in the correct places and the components accurately positioned. In the reflow stage, a suitable heating process is used to raise the temperature of the solder joint areas to, and past the solder alloy melting point for a sufficiently long time for the joint to form. It is vital that the PCB and components do not suffer from thermal degradation and that excess intermetallic growth does not occur at the solder interface.

The IR reflow soldering process occurs in several phases as the SMDs' to be soldered are carried through an IR furnace on a conveyor:-

a) Pre-heating stage - to drive off solvents and bring the assembly to be soldered close to the reflow temperature.

b) Equilisation stage - this step (or steps) allows the equilisation of the temperatures within the assembly before the short reflow stage which then melts the solder paste.

c) Cooling stage - the soldered assembly returns to room temperature, usually assisted by forced convection in a nitrogen atmosphere.

It is worth noting that the choice of the exact temperature profile has traditionally been based upon empirical data rather than any detailed knowledge of the heating process, and as such may not be the optimum for any individual design of PCB assembly.

Various authors [2] have reported that the IR reflow process results in significant variations in the temperature/time profile over the area of a typical PCB. These variations from the nominal IR profile are caused by the variations in for example the component positions, emissivity, conductivity, specfic heat capacity, the density and distribution of the PCB tracks, solder volume and also, the non-uniformity of the heater panels. These local variations may give rise to a whole range of soldering cerects such as tombstoning, wicking, leaching and solder balls $[3,4,5]$. Furthermore, the viscosity of the solder is temperature dependent. Therefore, temperature variations on the PCB will result in different wetting behaviours and lead to some of the problems mentioned earlier. Moreover, the initial microstructures of a resultant joint depends 
largely on the cooling rate [2] although there is still uncertainty as to the effects of the initial microstructures on the long term fatigue resistance.

Another important aspect of the IR reflow process is that, due to their greater surface area to volume ratio, the edges and in particlar the corners of the PCB will experience higher temperatures than the rest of the PCB. This difference in the temperatures has led to charring of the PCB edges in some circumstances.

It is the aim of this work to model the IR reflow process and hence obtain a better understanding of the activity and identify the variations in the thermal profiles that occur and assess their significance. It is also the aim of this work to investigate the use of thermal components (heat thieves/barriers) to alter the thermal capacity distribution within the PCB. The simple use of such components can reduce temperature differences such that the same temperature/time profile is experienced irrespective of the position on the board.

\section{THE MODEL}

The present model has been developed using SDRC I-DEAS pre/post processing software and Maya Heat Transfer Technologies TMG Thermal Model Generator. TMG is a finite difference thermal analysis system which was originally developed for modelling heat flows in satellite systems and consequently has good facilities for solving transient radiative heat transfer problems. The TMG modelling system is also able to model fluid flows such as the forced convection cooling of PCBs' at the end of the reflow process and latent heat absorption/generation due to phase changes such as the melting of the solder paste. The system accepts input in the form of finite element data and this allows geometrically complex models to be easily created using a solid modelling system such as I-DEAS.

The present model (see also ref.6) consists of two seperate structures: the furnace and the basic PCB assembly. The furnace modelled is a Surf Systems IRM150 with 6 panel heater zones and a forced air cooling stage. The speed at which the PCB passes through the furnace is $300 \mathrm{~mm}$ per minute. The temperature profile of the furnace is set to step changes from $25^{\circ} \mathrm{C}$ to $200^{\circ} \mathrm{C}$ and again back to $25^{\circ} \mathrm{C}$. The PCB modelled for testing purposes is $179 \mathrm{~mm}$ by $230 \mathrm{~mm}$ and made from $1.6 \mathrm{~mm}$ thick FR4 (a flame-retardant grade of epoxy resin reinforced with glass cloth). As for the thermal components, the dimensions are $230 \mathrm{~mm}$ by $20 \mathrm{~mm}$ for the guard strips and $230 \mathrm{~mm}$ by $179 \mathrm{~mm}$ and $33 \mathrm{~mm}$ in the ring width for the guard rings. Figure 1 is a schematic diagram showing the furnace, PCB and the radiative links between the furnace and the PCB.These

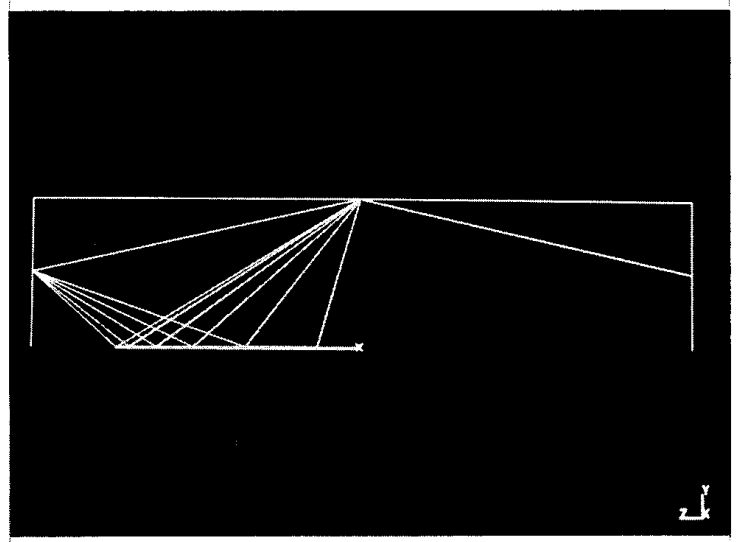

FIGURE 1. Schematic diagram showing the furnace, $P C B$ and the radiative links between the furnace and the PCB. structures are thermally interlinked by radiative heat transfer relationships. Measurement has shown that the air temperature near to the PCB is very close to the PCB temperature during ramp up to reflow. This indicated that air convection was not significant during this phase of the process. The analysis of the model requires the calculation of the view factors $V_{i j}$ ( the fraction of the radiation emmitted by a surface $i$ that is intercepted by surface $j$ ) between each element of the model and all other elements. This calculation is computationally intense (especially where there is shadowing such as that when a component covers part of a PCB). In order to avoid the repeated calculation of these view factors as the PCB moves through the furnace, the model has been designed such that the PCB is fixed at the centre of a furnace of twice the length of the actual furnace and the temperature of the individual heating panels are varied in order to simulate motion through the furnace. Further savings in the CPU time are achieved by utilising the symmetry of the PCB and modelling only half of its area.

\section{RESULTS}

The presentation of results from the model is divided into three sections: bare boards of FR4, copper, graphite and alumina. Copper, graphite and alumina guard strips attached to a FR4 PCB and a third set with similar guard rings on a FR4 PCB.The three types of materials were chosen as the thermal components because of their wide ranging thermal properties which can tailor the thermal profiles in contrasting manners. The thermal properties which are of importance in this work are: emissivity, thermal conductivity and volumetric heat capacity (density $x$ specific heat capacity)

\section{BARE BOARDS}

The temperature profiles of the four types of boards as mentioned earlier are presented in figures 2-5. The whole of the copper and graphite boards have reached temperatures of $182^{\circ} \mathrm{C}$ and $198^{\circ} \mathrm{C}$ respectively (see figures $3 \& 4$ ) whereas there are temperature spreads of $29^{\circ} \mathrm{C}$ and $13^{\circ} \mathrm{C}$ within the FR4 and alumina boards respectively (see figures $2 \& 5$ ). It is worth noting that the magnitude of the temperature of the alumina board is around $30-40^{\circ} \mathrm{C}$ lower than the other three under identical conditions.

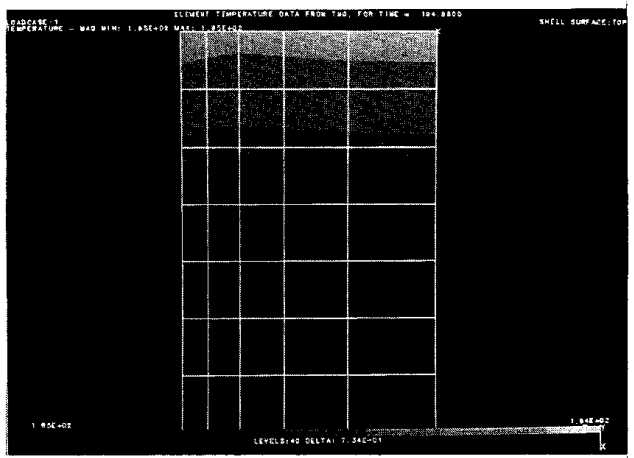

FIGURE 2.Temperature profile of a FR4 PCB at time $=195 \mathrm{~s}$.

\section{GUARD STRIPS}

The temperature profiles of the FR4 bare board with attached copper, graphite and alumina strip on its outer edge are presented in figures 6-8 respectively. It can be observed that the original FR4 profile has been modified significantly. For the board clamped with an alumina strip, the temperature gradient of the PCB has been reduced to less than about five degrees with the strip being 'cold' at around $143^{\circ} \mathrm{C}$ (see fig.8). On the other hand, a thermal gradient still exists between the leading and trailing edges of the boards clamped 
with a copper and graphite strip respectively (see figures $6 \& 7$ ). It can be observed in fig.7 that the graphite strip is at $194^{\circ} \mathrm{C}$ with most of the PCB at a lower temperature of between $179^{\circ} \mathrm{C}$ and $188^{\circ} \mathrm{C}$ This is the reverse of the alumina case mentioned earlier.

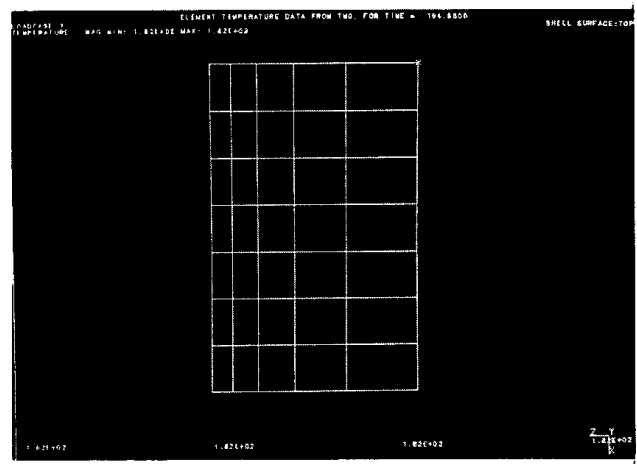

FIGURE 3. Temperature profile of a copper PCB at time $=195 \mathrm{~s}$.

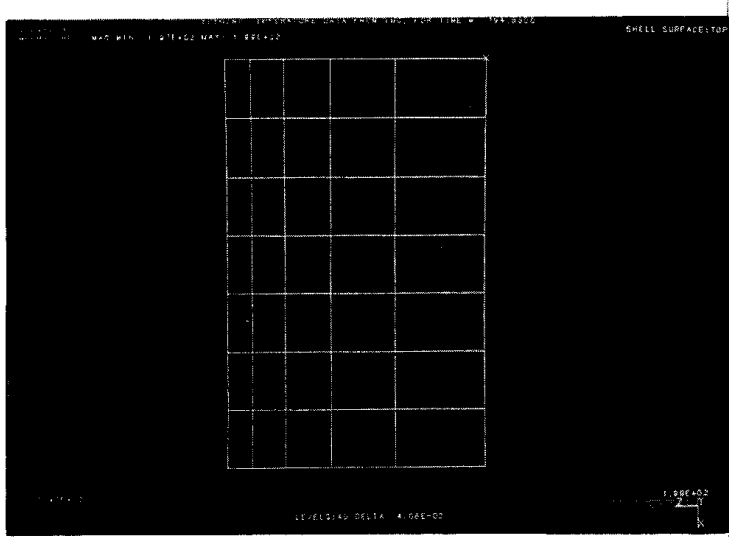

FIGURE 4. Temperature profile of a graphite $\mathrm{PCB}$ at time $=195 \mathrm{~s}$.

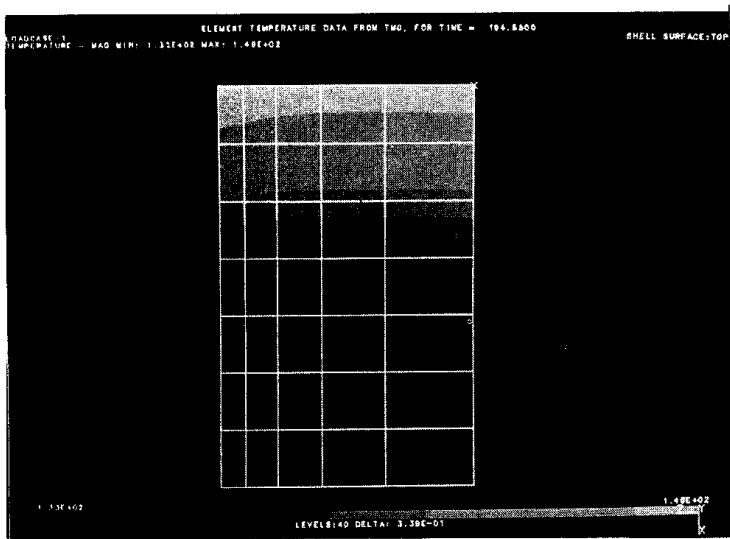

FIGURE 5. Temperature profile of a alumina $\mathrm{PCB}$ at time $=195 \mathrm{~s}$.

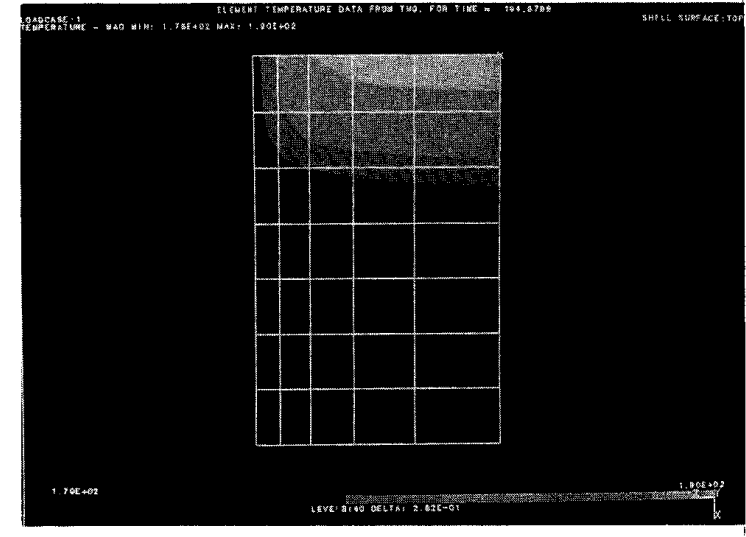

FIGURE 6. Temperature profile of a FR4 PCB(centre) attached with a copper guard strip (outer left hand side) at time $=195 \mathrm{~s}$.

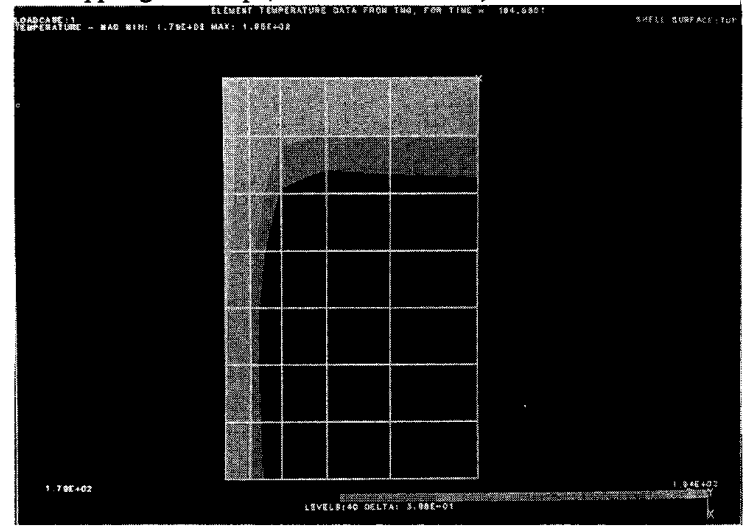

FIGURE 7. Temperature profile of a FR4 PCB(centre) attached with a graphite guard strip (outer left hand side) at time $=195 \mathrm{~s}$.

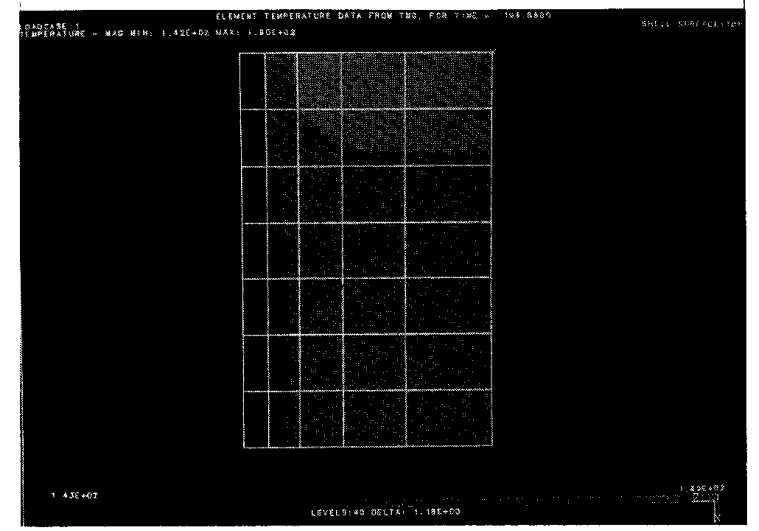

FIGURE 8. Temperature profile of a FR4 PCB(centre) attached with a alumina guard strip (outer left hand side) at time $=195 \mathrm{~s}$. 


\section{GUARD RINGS}

The effects of clamping the FR4 PCB with copper; graphite and alumina in an annular formation are presented in figures 9-11. The contrasting effects which the graphite and alumina rings (figures 10 \& 11) have on the thermal profiles are again apparent (as mentioned earlier in section 3.2). It can be noted from fig.9 that the temperature difference between the board and the copper ring is the smallest (the difference is about $10^{\circ} \mathrm{C}$ ) amongst the three types of rings investigated.

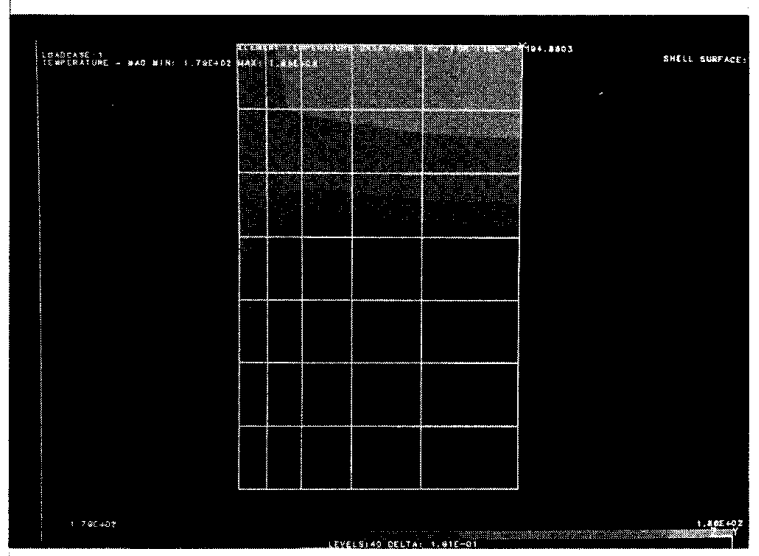

FIGURE 9. Temperature profile of a FR4 PCB(centre) attached with a copper ring (outer edges) at time $=195 \mathrm{~s}$.

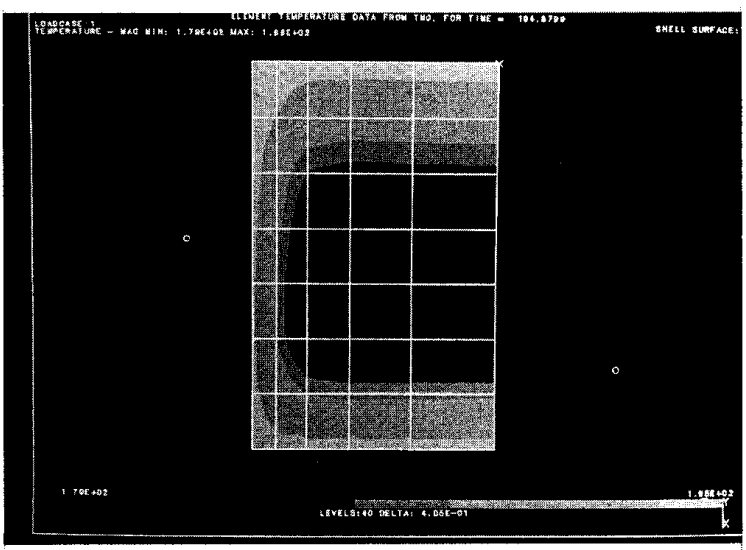

FIGURE 10. Temperature profile of a FR4 PCB(centre) attached with a graphite ring (outer edges) at time $=195 \mathrm{~s}$.

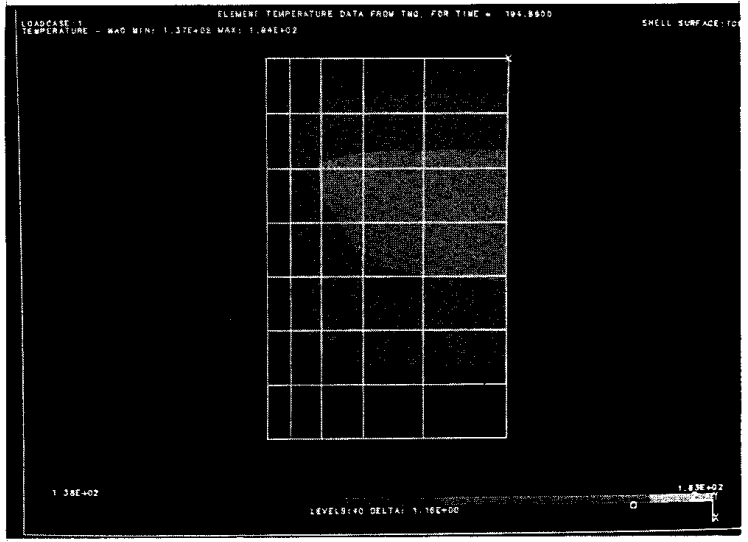

FIGURE 11. Temperature profile of a FR4 PCB(centre) attached with a alumina ring (outer edges) at time $=195 \mathrm{~s}$.

\section{DISCUSSION}

Two points should be considered to assist in understanding the heating processes in the reflow of a complex and heat-sensitive printed circuit board. First, the temperature differentials are almost solely a function of the heating rate for any given assembly; the slower the heating rate, the less will be the temperature differential. Secondly, these differentials disappear to within a couple of degrees for any system when it is in thermal equilibrium. However, when using infra-red radiation as the thermal energy source, the reflow process is arrested before equilibrium is achieved since it is an excess heating, rather than an equilibrium heating method. This means that a well defined temperature/time cycle must be decided upon and the process control must be capable of reliably maintaining that cycle.

Moreover, in the rapid thermal processing of semiconductor wafers by for example, optical annealing using an incoherent light source (halogen lamps), the use of graphite 'guard rings' clamped around the wafers are common. This has the effect of reducing the thermal gradient both along a cassette of wafers and also across a single wafer. The number of crystallographic slips in a wafer is critical in determining the production yield of working devices [7]. By using a similar principle, it has been observed from the work here that the thermal profiles of a SMD assembly can be tailored. This is achieved through the use of three different types of guard strips and rings made of copper, alumina and graphite. The material properties of these rings are presented in Table 1.

Alumina is used as the substrate material in hybrid microelectronics technology. These ceramic substrates have the same Temperature Expansion Coefficient (TEC) as the ceramic components and so much of the problem of differential expansion is alleviated. In this case, however, alumina appears to act as a heat barrier to the FR4. It has been shown that the use of an alumina strip has the effect of tailoring the profiles and generating an even temperature around the PCB (see figure 8). However, the difficulty at which the alumina can be incorporated into the existing surface mount manufacturing processes may hinder its use although its use as a ceramic substrate in hybrid microelectronics is a mature technology. Also, the 
temperature difference between the PCB and the alumina strip can be significant (see figures $8 \& 11$ ) and may cause mismatch problems because its TEC is about half that of FR4 (see Table 1).

\begin{tabular}{|l|c|c|c|c|}
\hline MATERIAL & FR4 & COPPER & ALUMINA & GRAPHITE \\
\hline EMISSIVITY & 0.94 & 0.78 & $0.3-0.5$ & 0.79 \\
\hline $\begin{array}{l}\text { THERMAL } \\
\begin{array}{l}\text { EXPANSION } \\
\text { COEFFICIENT } \\
\text { (10E-6.K-1) }\end{array}\end{array}$ & $15 \mathrm{E}-6$ & $16 \mathrm{E}-6$ & $6.4 \mathrm{E}-6$ & $1.6 \mathrm{E}-6$ \\
\hline $\begin{array}{l}\text { DENSITY } \\
\text { (kg.m-3) }\end{array}$ & 2000 & 8900 & 3700 & 2250 \\
\hline $\begin{array}{l}\text { SPECIFIC } \\
\text { HEAT } \\
\text { (J.kg-1.K-1) }\end{array}$ & 2000 & 380 & 1180 & 711 \\
\hline $\begin{array}{l}\text { THERMAL } \\
\text { CONDUCTIVITY } \\
\text { (W.mK-1) }\end{array}$ & 1 & 370 & 35 & 100 \\
\hline
\end{tabular}

TABLE 1. Material data for FR4 and the three different types of guard strips / rings.

A copper strip or ring may therefore be a better alternative as it is easier to incorporate in the manufacturing processes. Moreover, it has the advantage of thermal match with the FR4 PCB. Temperature differentials should be less of a problem in the case of the copper ring because it can be observed from figures 6 and 9 that the temperature differences are only about $10^{\circ} \mathrm{C}$.

Although graphite strip and ring can both be used to tailor the thermal profiles of the FR4 PCB (see figures 7 and 10), it is not practical to use this material in a high-volume and automated manufacturing environment as graphite is extremely brittle and would be difficult to attach to the PCB. It is important to note that the model and calculations are based on perfect attachment of the guard strips and rings onto the edges of the FR4 PCB.

It can be summarised that the alumina guard strip and ring have the effect of creating a 'thermal barrier', i.e. the radiant heat from the furnace panels is trapped in the centre of the PCB and is used to heat up the PCB uniformly in excess of $185^{\circ} \mathrm{C}$ (see figures $8 \& 11$ ). This implies that the joints of components positioned at the centre of the PCB are likely to experience similar temperature/time profiles. This may well reduce the defect rate as thermal gradients across a PCB has been identified as one of the principle causes for reflow soldering problems. On the other hand, the graphite strip and ring act as heat sinks. The temperature of the PCB is observed to be cooler at the centre $\left(179^{\circ} \mathrm{C}\right)$ than at the graphite strip and ring $\left(195^{\circ} \mathrm{C}\right)$. More importantly, the melting point of $\mathrm{SnPb}(60 / 40)$ solder is around 183 and $189^{\circ} \mathrm{C}$. Therefore, as a result of mounting the graphite strip and ring, the temperature at the centre of the PCB is now below that required for reflow ( see figures $7 \& 10$ ). This can be accomodated however, by raising the temperature of the furnace emmitters.

\section{CONCLUSIONS}

It has been demonstrated that it is practical to apply modelling techniques to the IR reflow soldering process; further refinements of the model are expected to find application both in process optimisation and in further studies of solder joint formation.

It has also been shown that the thermal profiles of PCBs' can be tailored by the incorporation of 'thermal components'. In this work, it has been demonstrated that these thermal components can both act as heat sinks (graphite) as well as thermal barriers (alumina).
Significant improvements in reducing the thermal gradient to less than five degrees on the PCB has been achieved through the use of alumina guard strip and ring. This implies that the joints of components should experience similar temperature/time excursions in all areas of the PCB. The inclusion of chip and other components onto unclamped and clamped PCBs' and experiments to verify the effects of these 'thermal components' form the focus of future work.

It is anticipated that this type of modelling and the application of thermal components could eventually be used on a routine basis for checking/optimising new PCB designs for manufacture. This will require the establishment of a database of component thermal properties under manufacturing conditions.

\section{ACKNOWLEDGEMENTS}

This work is carried out in collaboration with Dr.P.M.Sargent and Mr.P.P.Conway of Cambridge University and Loughborough University of Technology, England respectively.

The authors would also like to acknowledge the enthusiatic support of our project partners in this work: Alphametals, Avantel, British Aerospace, Cambridge Consultant Ltd., Cambridge Electronics Industries, IBM (Greenock), the National Physical Laboratory, Raychem, SDRC, the Surface Mount Club and Racal Redac, and the financial support of the Application of Computers to Manufacturing Engineering (ACME) Directorate of the Science and Engineering Research Council (SERC).

\section{REFERENCE}

[1] P.P.Conway, D.J.Williams, A.C.T.Tang, P.M.Sargent and D.C.Whally."Process variables in the reflow soldering of surface mount." IEEE IEMTS 8th International Electronic Manufacturing Technology Symposium, Stressa 7-9th,May 1990.

[2] M.Nylen and S.Norgren."Temperature variations in soldering and their influence on microstructure and strength of solder joints." Soldering \& SMT No.5June(1990).

[3] D.Hey et al. "Making the right choice for reflow technologies." Electronics Manufacture and Test, June 1989.

[4] A.Gothard et al. "Reflow soldering, the heat goes on." Electronics Manufacture and Test, June 1988

[5] A.N.Arslancan, D.K.Flattery. "Infra-red reflow for SMT,1\&2." Electronics Production, May \& June 1988.

[6] D.C.Whalley, P.P.Conway \& D.J.Williams. "Thermal modelling of temperature development during the reflow soldering of SMD assemblies." Proc.International Microelectronic Conference,Tokyo (1990).

[7] C.Russo. "Rapid Thermal Processing - where has it been? Where is it going?" Nucl.Inst.\& Mets.in Phys.Res.B6(1985)P.298. 